\title{
Stem cells for the treatment of neurodegenerative diseases
}

Elise Dantuma, Stephanie Merchant and Kiminobu Sugaya*

\begin{abstract}
Stem cells offer an enormous pool of resources for the understanding of the human body. One proposed use of stem cells has been as an autologous therapy. The use of stem cells for neurodegenerative diseases has become of interest. Clinical applications of stem cells for Alzheimer disease, Parkinson disease, amyotrophic lateral sclerosis, and multiple sclerosis will increase in the coming years, and although great care will need to be taken when moving forward with prospective treatments, the application of stem cells is highly promising.
\end{abstract}

\section{Introduction}

Since their discovery, stem cells have altered the perception of the human body and revolutionized medical research. The understanding of how the human body develops and repairs itself has improved [1]. Because of this, we are able to expand upon the possibilities of stem cell use within the human body. As a result, interest in stem cells as therapies has increased [1].

Research into the use of stem cells for the treatment of neurodegenerative diseases, such as Alzheimer disease (AD), Parkinson disease (PD), amyotrophic lateral sclerosis (ALS), and multiple sclerosis (MS), has become a growing interest in the medical community. Each of these diseases affects different areas and structures of the central nervous system (CNS). An extensive initiative to investigate stem cells as possible treatments for these four diseases has occurred. Stem cells hold a great opportunity for each of these diseases as a form of replacement or protective therapy. Although this is not meant to be an all-inclusive review of current stem cell research within neurodegenerative disease, we review the major

*Correspondence: ksugaya@mail.ucf.edu

Burnett School of Biomedical Sciences, College of Medicine, University of Central Florida, 6900 Lake Nona Boulevard, Orlando, FL 32827, USA opportunities and obstacles stem cells hold for the future of treatments for AD, PD, ALS, and MS.

\section{Stem cells and their opportunities and limitations}

Stem cells were discovered in the early 1960 s $[2,3]$, and knowledge about their characteristics and composition has come a long way. Stem cells are generally defined as cells that are capable of self-renewal and that possess the ability to differentiate into multiple types of cells. On the basis of their differentiation abilities, stem cells can be classified as totipotnet, pluripotent, or multipotent. Totipotent stem cells are capable of differentiating into any type of cell within the body, including extra-embryonic tissue, and can be isolated from only the four-cell stage of the embryo. Isolated from the blastocyst of the embryon, pluripotent stem cells are capable of differentiation into any cell within the body, and so they are able to give rise to cells from any of the three major tissue lineages: ectoderm, mesoderm, and endoderm. Multipotent stem cells are capable of differentiation into only the select types of cells from which they are derived and can be isolated from various sources within the adult human body. As the human body develops, the margin of differentiation capability begins to be reduced from a totipotent state to a pluripotent state and lastly to a multipotent capability.

Naturally occurring stem cells generally include embryonic stem cells (ESCs), fetal stem cells (FSCs), and adult stem cells. Obtained from the blastocyst, ESCs are pluripotent and proliferate quite well in culture. Given these two qualities, ESCs appear to offer both a significant number of cells and the ability to germinate into a variety of different cell types [4]. ESCs have the most ability to be used in a clinical setting since they are able to give rise to multiple types of cells; however, there are multiple ethical concerns with their use $[5,6]$ and the risk of adverse reactions, such as an immune reaction or tumor formation or both [7].

As a source of multipotent stem cells, fetal organs contain FSCs. The several advantageous qualities of FSCs include their adaptability to their environment, migration capabilities, lack of teratoma formation, and rejections in vivo [8]. 
Adult stem cells are classically defined as multipotent cells, which are defined by their tissue of origin. Multiple areas within the adult body, including bone marrow, muscle, brain, and liver, contain an endogenous adult stem cell population [1]. The key benefit of adult stem cells is their potential use in autologous therapies, in which cells can be harvested and used within the same patient. This benefit eliminates the ethical concerns and risks that ESCs bear. As advantageous as adult stem cells appear to be, the limited differentiation ability restricts universal use within the body.

Because naturally occurring stem cells have limitations, scientists have developed a method for increasing pluripotency within non-pluripotent cells. The latter cells are termed induced pluripotent stem (iPS) cells, and multiple studies cite the reprogramming process that uses specific transcription factors, such as Oct4, Sox2, $K l f 4$, and $c-M y c$, to induce pluripotency [9-12]. Some argue that the use of only two of these factors is sufficient for iPS cell formation [13,14]. iPS cells open up the possibility of using a patient's own somatic cells, through reprogramming, for treatment. However, iPS cells have limitations as well. First, the process of creating these types of cells is low in efficiency [15]. The fact that a large number of starting cells are needed for the reprogramming process makes this a challenging beginning. Second, the use of viruses for transduction of the pluripotency factors within iPS cells poses a problem of possible integration into the host genome if these factors become reactivated [16]. Lastly, iPS cells have the ability the produce teratomas, although the risk is less significant compared with ESCs [16]. Researchers have attempted to address these disadvantages. The low efficiency of reprogramming iPS cells may be related to the p53mediated DNA damage [17], and so inhibiting p53 may increase the conversion of the cells but may increase the risk of tumorigenesis from iPS cells as well. The second issue has been attacked in two ways. One is to use nonviral transfection [18], although the efficacy still needs to be worked out and long-term control of the gene expression may be difficult. Another approach would be the use of Cre-recombinase excisable viruses [19] or delivery of recombinant protein [20]. However, we still must prove the functionality and safety of the resulting cells, and stem cell-based therapy may still have hurdles to overcome but its future is very promising.

\section{Stem cells and neurodegenerative diseases}

Neurodegenerative diseases hold an opportunity for the clinical use of stem cells. In neuroscience, the discovery of neural stem cells (NSCs) and subsequent research [21] have nullified the previous idea that the adult CNS was not capable of neurogenesis [22,23]. Indeed, neurogenesis occurs throughout life. NSCs are believed to reside within the subventricular zone of the lateral ventricle wall and the subgranular zone of the hippocampal dentate gyrus, where neurogenesis occurs [22,24]. NSCs give rise to glial-restricted precursors (GRPs) and neuronrestricted precursors, both of which differentiate into astrocytes, oligodendrocytes, or neurons [23]. Another study demonstrated that transplanted NSCs isolated from a 9-week-old human fetus have the ability to differentiate into neural cells and improve cognition in aged rats [25]. Hence, the idea of using NSCs for neurodegeneration treatment is intriguing.

However, NSCs are not so easy to access as a source of stem cells for possible use to treat neurodegenerative diseases. Previously, many studies have suggested the use of bone marrow-derived mesenchymal stem cells (MSCs) for regeneration of neural cells since MSCs are present in bone marrow and are relatively easily accessible within the human body. However, the consensus now is that naive MSCs do not become neural cells. Our previous study suggests that MSCs can be dedifferentiated into cells similar to iPS cells by increasing the expression of a single ESC gene, nanog. We were able to transdifferentiate MSCs into neural cell lineage after dedifferentiation. This result indicates that we may be able to use adult stem cells as an autologous source to create iPS cells. This technology and iPS cells together may offer the potential for autologous neuroregenerative therapies to be developed along with the ease of access to a patient's own cells. Another key factor for the development of stem cell treatments for neurological diseases will be the understanding of the pathology of the specific disease. Each disease will need to be assessed individually and each treatment will need to be tailored accordingly.

\section{Alzheimer disease}

As one of the most common causes of dementia, AD affects 5.3 million Americans [26]. AD, known for its quintessential hallmarks of amyloid- $\beta$ peptide $(A \beta)$ plaques and neurofibrilary tangles [21,27-29], results in the death of several types of neuronal lineage cells within multiple regions of the brain [29-31], specifically cholinergic neurons [23]. Discovered in 1987, the human amyloid precursor protein (APP) gene is located on chromosome 21 and codes for a type I transmembrane protein [32]. A $\beta$ plaques are generated by $\gamma$ - and $\beta$ secretases that cleave APP at specific amino acids [33], and neurofibrilary tangles are composed of tau proteins that are hyper-phosphorylated, resulting in neuron impairment [34]. Both of these hallmarks lead to cognitive impairment and loss of memory [29]. However, the direct pathogenesis of AD still eludes researchers [35].

Currently available drugs for the treatment of $\mathrm{AD}$ are purely for symptoms [36] and among these drugs are the cholinesterase inhibitors [33,37]. After acetylcholine is 
released from the synapse, cholinesterase inhibitors delay its degradation, leading to improved cognition [33]. However, these types of drugs have only a modest effect, which can be variable among patients [38]. Another type of drug available for AD patients is an $N$-methyl-Daspartate (NMDA) receptor antagonist named memantine [33]. Memantine prevents the NMDA receptors from overstimulation that can lead to toxicity [33]. Since the current treatments have only marginal effects and greatly vary in their effectiveness in patients, the need for new treatments is great. It is estimated that there will be 615,000 new cases by 2029 and 959,000 by 2050 [26]. Owing to this increase in the number of new cases, a great burden will be placed on health-care systems [26]. The need for a proper treatment or cure for $A D$ is imperative.

Recently, Blurton-Jones and colleagues [29] published a study in which they injected NSCs into the hippocampal regions of the brain of both a transgenic $A D$ mouse model and an age-matched non-transgenic mouse model. Interestingly, the mice improved in cognitive function and there was no change to the existing $A \beta$ plaques or neurofibrilary tangles [29]. Instead, the authors discovered brain-derived neurotrophic factor, which is important for neuron outgrowth, and synapse formation increased [39], leading to improved cognition through increased synaptic density [29]. This demonstrated cognition could be improved without the need for modifying the existing pathological conditions [29].

Although the physiological function of APP is not clear, recent reports indicate that it may play an important role in regulating stem cell biology or adult neurogenesis [40]. We found that APP increased chemokine levels to alter cell migration [41]. We also showed that increased APP caused glial differentiation of human NSCs in vitro and in vivo. This may create the problem of how to regenerate neurons by augmentation of NSCs when APP levels are high. Also, increased levels of APP, found in Down syndrome patients, who develop AD in later life, may exhaust endogenous NSC populations because of increased premature glial differentiation of the cells [42]. This APP function may need to be considered for neuroregenerative therapies under a pathogenic APP environment within the $\mathrm{AD}$ brain. Increased levels of APP in the brain not only reduce NSCs, which may increase the risk of $\mathrm{AD}$, but also increase the level of glial differentiation of stem cells upon transplantation, reducing the efficacy of therapy to improve cognitive function $[42,43]$. Thus, the levels of APP may need to be reduced before transplantation of stem cells, and our previous study showed significant neurogenesis from NSC transplantation in APP transgenic mice but only after APP level was reduced by phenserine treatment [34]. NSCs may also be useful to augment growth factors. A transgenic model of $\mathrm{AD}$ showed improvement in cognition by release of BDNF (brain-derived neurotrophic factor) after NSCs [29]. NSCs are also reported to express neurotrophic factors and promote axonal growth in spinal cord injury [44].

Many experimental studies show a beneficial neuroprotective effect of hemopoietic growth factors such as granulocyte colony-stimulating factor (G-CSF), erythropoietin (EPO), granulocyte-macrophage colony-stimulating factor (GM-CSF), stem cell factor, vascular endothelial growth factor (VEGF), and stromal cell-derived factor-1-alpha (SDF-1-alpha) in ischemic stroke $[45,46]$. Bone marrow-derived MSCs are reported to protect or reduce ischemic damage by releasing insulin-like growth factor-1 (IGF-1) in transient ischemic model animals. Furthermore, NSCs modified by transfection of vascular endothelial growth factor provided neuroprotection after transient focal cerebral ischemia [47]. Despite promising results from animal models, the lack of data in humans hampers efficacy assessments of growth factors on neurodegenerative disease therapy. In clinical study with stroke patients, MSC-treated patients showed significant and consistent improvement in the Barthel index and modified Rankin score over the control patients during the follow-up period up to 12 months [48]. More recently, a long-term follow-up study of intravenous autologous MSC transplantation in patients with ischemic stroke showed very promising results [49]. These results may support the use of stem cells to augment growth factor in $\mathrm{AD}$ in the future.

\section{Parkinson disease}

First described in 1817, PD, the second most common neurodegenerative disease [50], is a neurological degenerative disease that results in the loss of dopaminergic neurons within the substantia nigra [51,52], leading to a loss of motor function. Lewy body formation and neuritis are the pathological hallmarks of this disease, and the specific etiology is still unknown [52]. PD itself is not fatal but complications from the disease can lead to death.

Current treatments for PD include drug regimens and surgery. However, these treatments are purely palliative. The current drug treatment for PD supplies the surviving dopamine neurons with L-Dopa, which they convert to dopamine [53]. Eventually, however, all of the remaining dopamine neurons die and treatment with L-Dopa is ineffective [53].

MSCs have been proposed as a potential treatment for PD. Park and colleagues [54] investigated the use of MSCs in a PD mouse model to observe a potential neuroprotective effect on neuronal loss. MSCs significantly preserved the number of dopaminergic neurons and tyrosine hydroxlase-positive cells in vitro and in vivo [54]. 
In a different study, Murrell and colleagues [55] proposed the use of adult olfactory stem cells for recovery of dopaminergic neurons in PD. The adult olfactory stem cells were differentiated into NPCs and were capable of becoming dopaminergic-like neurons both in vitro and in vivo [55]. NSCs have also been investigated for their use as possible treatments for PD. Yasuhara and colleagues [56] tested the use of NSCs on the behavioral benefits and protective effects in PD in vivo. When NSCs were immediately transplanted after 6-hydroxydopamine lesion formation in mice, tyrosine hydroxlase neurons were protected and PD symptoms were reduced [56].

The study of Kim and colleagues [57] supports the use of ESCs for cell replacement therapy as the authors have shown that highly enriched populations of midbrain NSCs can be derived from mouse ESCs. The dopamine neurons generated by these stem cells show electrophysiological and behavioral properties expected of neurons from the midbrain [57]. To move forward with these studies, further experiments must be developed to show methods of enriching the cell of interest and demonstrate that these cells show functions that will assist in treating the disease.

Other studies have investigated the use of iPS cells, derived from mouse fibroblasts, to produce neural progenitor cells, which are multipotent adult stem cells, for injection into 6-hydroxydopamine-lesioned rats [58]. The injected derived iPS cells were capable of migration to various areas of the brain, differentiated into glia and neurons, and integrated into the host brain [58]. Additionally, the efficiency of their experiment was high, and almost all of the animals showed high numbers of tyrosine hydroxlase-positive cells [58]. The study of Iacovitti and colleagues [59] supports this by deriving midbrain dopaminergic (mDA) neurons from a commercially available human induced pluripotent stem (hiPS) cell line, IMR90 clone 4 . The authors were able to produce cells that followed the same lineage pathway as H9 human ESCs and that showed the same expression levels of dopamine and DOPAC (dihydroxyphenylacetic acid) [59]. The mDA hiPS cells that were transplanted into 6-OHDA-leisioned PD rats not only survived in the long term but also integrated into the host brain, but it was also noted that many Nestin ${ }^{+}$tumor-like cells remained at the site of graft [59]. The future success of cell replacement therapies for PD will depend on the ability to select the appropriate $\mathrm{mDA}$ cell lineage.

\section{Amyotrophic lateral sclerosis}

ALS, also known as Lou Gehrig's disease, is a neurodegenerative disease affecting the spinal cord and brain stem and typically is adult-onset. Specifically, the upper and lower motor neurons die, leading to progressive paralysis [60]. Over 150 years ago, the classic hallmarks of this disease, including the death of motor neurons and progressive atrophy, were described [50]. Generally, the mean onset age is 55 years, and prognosis after diagnosis is only 2 to 5 years [50]. The cause of ALS is still unknown.

In 2006, Chi and colleagues [61] performed a study that observed the role of neural progenitor cells in an ALS disease mouse model. Interestingly, the degeneration of the motor neurons stimulated neurogenesis and neural progenitor cell proliferation [61]. In another study, Corti and colleagues [62] transplanted NSCs positive for both Lewis $\mathrm{X}$ and a chemokine receptor into the spinal cord. Disease progression was delayed and survival time increased for transplanted mice because of an integration of the transplanted cells into the spinal cord [62]. These studies may indicate that neurotropic factors produced by transplanted stem cells protect neurons from the environment of ALS and increase neurogenesis. Since abnormality of astrocytes is one of the hallmarks of ALS, replacement of glia cells by adult glial progenitors [63] and GRPs [64] has been proposed. Studies by Maragakis and colleagues [63] and Rothstein and colleagues [64] show that astrocyte dysfunction occurs in human ALS and SOD1 ${ }^{\text {G93A }}$ animal models. The authors showed success in transplantation of lineage-restricted astrocyte precursors, GRPs. GRPs not only survived in the diseased environment but also differentiated into astrocytes and reduced microgliosis in SOD $1^{\mathrm{G} 93 \mathrm{~A}}$ rat cervical spinal cord [64]. These findings demonstrate the potential ability for transplantation-based astrocyte replacement and show that cell transplantation to the cervical spinal cord is a promising therapeutic strategy for slowing focal motor neuron loss associated with ALS [64]. These preclinical animal studies are promising and may develop into clinical applications in the near future. On the other hand, replacement of degenerating motor neurons may create some controversy because of the lack of knowledge of whether the patients' cells produce healthy motor neurons and the ability of these cells to survive under the pathological condition. A recent study gives us an optimistic view of the development of neuroregeneration therapy of ALS. Dimos and colleagues [65] successfully produced motor neurons from iPS cells derived from an 82-year-old patient with familial ALS.

In 2008, Mazzini and colleagues [66] published a clinical-based experiment in which MSCs were autologously transplanted to ALS patients through a spinal cord injection. The authors state that the results of this study show that MSCs are safe for clinical use for treatment of ALS and showed a slowing in the decline in the forced vital capacity and functional rating scores of some patients [66]. However, as the study notes, this experiment was performed on a small number of patients and will need to be replicated with a large number of patients 
in order to verify the results [66]. Mazzini's group [67] did replicate this experiment with a larger number of patients, publishing the results in 2010. Although similar results were obtained, the study lacked significant changes in the progression of the disease, which were obtained in the previous study [67].

\section{Multiple sclerosis}

One of the major qualities of MS, a CNS autoimmune disease, is the initial relapse-remitting cycle of the disease, eventually leading to progression of the disease without relapses [68]. The myelin sheath, the primary target, is degraded and this degradation affects neurons [50]. Unlike AD, PD, and ALS, MS predominately affects young adults and has a higher rate of occurrence in females [50]. MS is also a heterogeneous disease, and so the degree of the disease can range from fairly benign to extremely debilitating and the stages of disease can range from only relapses to progressive [68]. Again, currently available treatments are purely symptomatic.

Current approaches for MS treatment include monoclonal antibodies, chimeric molecules, and hematopoietic stem cells (HSCs) [69]. The general aim of HSCs for MS treatment is to completely correct the immune system anomaly within the patient [69]. A study by Aharonowiz and colleagues [70] investigated the use of human ESCderived neural precursor cells into the cerebral ventricles of an MS mouse model. The transplanted human ESCderived neural precursor cells reduced the clinical signs of MS and had a neuroprotective effect by immunosuppression within the mice [70].

The use of myelin-forming cell transplantation to restore myelin at sites of myelin loss has been experimented with since the 1970s [71]. However, the myelin-forming cells, especially those cells that are linage-restricted, are very limited in their growth and ability to regenerate myelin [71]. Therefore, stem cells might hold the answer for cell transplant treatments in MS [71]. In 2009, Burt and colleagues [72] published a study in which non-myeloablative HSCs were autologously transplanted to relapse-remitting MS patients. Neurological improvement and a slowing in progression were observed after transplantation [72].

\section{Conclusions}

Clinical application of stem cells, whether ESCs, FSCs, adult stem cells, or iPS cells, is increasingly becoming a reality. However, great care will need to be taken when moving forward. The pathological environments of neurodegenerative diseases will need to be assessed to observe their effect on transplanted stem cells. Additionally, the migratory patterns of transplanted stem cells will need to be observed and possibly controlled. With movement toward clinical use of stem cells, protocols will have to undergo extensive scrutiny of their preclinical safety and benefit analyses, projected experiments, and informed consent protocols [73].

In 2008, the International Society for Stem Cell Research released a set of recommended guidelines for the development of stem cell-based treatments [74]. These recommendations include the use of experts in stem cell biology for peer review of research ranging from preclinical to clinical, emphasizing risks involved with stem cell-based therapies within the voluntary informed consent, new oversight criteria for medical innovative care that falls outside of the realm of a clinical trial, and the equality of benefits of stem cell treatments [74].

In regard to the number of clinical trials, the number of $\mathrm{AD}$ and PD versus ALS and MS clinical trials is highly skewed. The reason for this perhaps is that, once their condition is diagnosed, ALS and MS patients have a limited prognosis. AD and PD patients have a longer prognosis. Potentially, the US Food and Drug Administration is more inclined to initiate clinical trials for ALS and MS because of the risk-to-benefit relationship. However, an increase in clinical trails for $\mathrm{AD}$ and $\mathrm{PD}$ is inevitable because of the high cost of 'human life' these two diseases present, along with the financial burden of cost of care.

Although the issues presented above do need to be resolved before the clinical application of stem cells can be realized, the advancement of these technologies is building. The number of stem cell clinical trials will increase tremendously and conceivably some will become standard treatments.

\section{Abbreviations}

$A \beta$, amyloid- $\beta$ peptide; $A D$, Alzheimer disease; ALS, amyotrophic lateral sclerosis; APP, amyloid precursor protein; CNS, central nervous system; ESC, embryonic stem cell; FSC, fetal stem cell; GRP, glial-restricted precursor; hiPS, human induced pluripotent stem; iPS, induced pluripotent stem; mDA, midbrain dopaminergic; MS, multiple sclerosis; MSC, mesenchymal stem cell; NMDA, N-methyl-D-aspartate; NSC, neural stem cell; PD, Parkinson disease.

\section{Competing interests}

The authors declare that they have no competing interests.

\section{Authors' contributions}

ED contributed to the composition of the manuscript. SM contributed to the composition and editing of the manuscript. KS contributed to the conception, composition, and editing of the manuscript. All authors read and approved the final manuscript.

\section{Published: 10 December 2010}

\section{References}

1. Ehnert S, Glanemann M, Schmitt A, Vogt S, Shanny N, Nussler NC, Stockle U, Nussler A: The possible use of stem cells in regenerative medicine: dream or reality? Langenbecks Arch Surg 2009, 394:985-997.

2. Becker AJ, McCulloch EA, Till JE: Cytological demonstration of the clonal nature of spleen colonies derived from transplanted mouse marrow cells. Nature 1963, 197:452-454

3. Siminovitch L, McCulloch EA, Till JE: The distribution of colony-forming cells among spleen colonies. J Cell Physiol 1963, 62:327-336. 
4. Mimeault M, Hauke R, Batra SK: Stem cells: a revolution in therapeuticsrecent advances in stem cell biology and their therapeutic applications in regenerative medicine and cancer therapies. Clin Pharmacol Ther 2007, 82:252-264.

5. Juengst E, Fossel M: The ethics of embryonic stem cells--now and forever, cells without end. JAMA 2000, 284:3180-3184.

6. McLaren A: Ethical and social considerations of stem cell research. Nature 2001, 414:129-131.

7. Li JY, Christophersen NS, Hall V, Soulet D, Brundin P: Critical issues of clinical human embryonic stem cell therapy for brain repair. Trends Neurosci 2008, 31:146-153.

8. Mimeault M, Batra SK: Concise review: recent advances on the significance of stem cells in tissue regeneration and cancer therapies. Stem Cells 2006 , 24:2319-2345.

9. Eminli S, Utikal J, Arnold K, Jaenisch R, Hochedlinger K: Reprogramming of neural progenitor cells into induced pluripotent stem cells in the absence of exogenous Sox2 expression. Stem Cells 2008, 26:2467-2474.

10. Lowry WE, Richter L, Yachechko R, Pyle AD, Tchieu J, Sridharan R, Clark AT, Plath K: Generation of human induced pluripotent stem cells from dermal fibroblasts. Proc Natl Acad Sci U S A 2008, 105:2883-2888.

11. Okita K, Ichisaka T, Yamanaka S: Generation of germline-competent induced pluripotent stem cells. Nature 2007, 448:313-317.

12. Wernig M, Meissner A, Foreman R, Brambrink T, Ku M, Hochedlinger $K$, Bernstein $B E$, Jaenisch $R$ : In vitro reprogramming of fibroblasts into a pluripotent ES-cell-like state. Nature 2007, 448:318-324.

13. Huangfu D, Maehr R, Guo W, Eijkelenboom A, Snitow M, Chen AE, Melton DA: Induction of pluripotent stem cells by defined factors is greatly improved by small-molecule compounds. Nat Biotechnol 2008, 26:795-797.

14. Kim JB, Zaehres H, Wu G, Gentile L, Ko K, Sebastiano V, Arauzo-Bravo MJ, Ruau D, Han DW, Zenke M, Scholer HR: Pluripotent stem cells induced from adult neural stem cells by reprogramming with two factors. Nature 2008, 454:646-650.

15. Rolletschek A, Wobus AM: Induced human pluripotent stem cells: promises and open questions. Biol Chem 2009, 390:845-849.

16. Yamanaka S: A fresh look at iPS cells. Cell 2009, 137:13-17.

17. Marion RM, Strati K, Li H, Murga M, Blanco R, Ortega S, Fernandez-Capetillo O, Serrano M, Blasco MA: A p53-mediated DNA damage response limits reprogramming to ensure iPS cell genomic integrity. Nature 2009, 460:1149-1153.

18. Jia F, Wilson KD, Sun N, Gupta DM, Huang M, Li Z, Panetta NJ, Chen ZY Robbins RC, Kay MA, Longaker MT, Wu JC: A nonviral minicircle vector for deriving human iPS cells. Nat Methods 2010, 7:197-199.

19. Soldner F, Hockemeyer D, Beard C, Gao Q, Bell GW, Cook EG, Hargus G, Blak A, Cooper O, Mitalipova M, Isacson O, Jaenisch R: Parkinson's disease patientderived induced pluripotent stem cells free of viral reprogramming factors. Cell 2009, 136:964-977.

20. Zhou H, Wu S, Joo JY, Zhu S, Han DW, Lin T, Trauger S, Bien G, Yao S, Zhu Y, Siuzdak G, Schöler HR, Duan L, Ding S: Generation of induced pluripotent stem cells using recombinant proteins. Cell Stem Cell 2009, 4:381-384.

21. Zhongling F, Gang Z, Lei Y: Neural stem cells and Alzheimer's disease: challenges and hope. Am J Alzheimers Dis Other Demen 2009, 24:52-57.

22. Ma DK, Bonaguidi MA, Ming GL, Song H: Adult neural stem cells in the mammalian central nervous system. Cell Res 2009, 19:672-682.

23. Limke TL, Rao MS: Neural stem cells in aging and disease. J Cell Mol Med 2002, 6:475-496

24. Zhao C, Deng W, Gage FH: Mechanisms and functional implications of adult neurogenesis. Cell 2008, 132:645-660.

25. Qu T, Brannen CL, Kim HM, Sugaya K: Human neural stem cells improve cognitive function of aged brain. Neuroreport 2001, 12:1127-1132.

26. Alzheimer's Association: 2010 Alzheimer's disease facts and figures. Alzheimers Dement 2010, 6:158-194.

27. Waldau B, Shetty AK: Behavior of neural stem cells in the Alzheimer brain Cell Mol Life Sci 2008, 65:2372-2384.

28. Xuan AG, Luo M, Ji WD, Long DH: Effects of engrafted neural stem cells in Alzheimer's disease rats. Neurosci Lett 2009, 450:167-171.

29. Blurton-Jones M, Kitazawa M, Martinez-Coria H, Castello NA, Muller FJ, Loring JF, Yamasaki TR, Poon WW, Green KN, LaFerla FM: Neural stem cells improve cognition via BDNF in a transgenic model of Alzheimer disease. Proc Natl Acad SciU S A 2009, 106:13594-13599.

30. Boucherie C, Hermans E: Adult stem cell therapies for neurological disorders: benefits beyond neuronal replacement? J Neurosci Res 2009,
87:1509-1521

31. Kim SU, de Vellis J: Stem cell-based cell therapy in neurological diseases: a review. J Neurosci Res 2009, 87:2183-2200.

32. Thinakaran $\mathrm{G}$, Koo EH: Amyloid precursor protein trafficking, processing, and function. J Biol Chem 2008, 283:29615-29619.

33. Roberson ED, Mucke L: 100 years and counting: prospects for defeating Alzheimer's disease. Science 2006, 314:781-784.

34. Lee HG, Casadesus G, Zhu X, Castellani RJ, McShea A, Perry G, Petersen RB, Bajic V, Smith MA: Cell cycle re-entry mediated neurodegeneration and its treatment role in the pathogenesis of Alzheimer's disease. Neurochem Int 2009, 54:84-88.

35. Park DH, Eve DJ, Chung YG, Sanberg PR: Regenerative medicine for neurological disorders. ScientificWorldJournal 2010, 10:470-489.

36. Hampel $\mathrm{H}$, Broich $\mathrm{K}$ : Enrichment of $\mathrm{MCl}$ and early Alzheimer's disease treatment trials using neurochemical and imaging candidate biomarkers. J Nutr Health Aging 2009, 13:373-375.

37. Kadir A, Andreasen N, Almkvist O, Wall A, Forsberg A, Engler H, Hagman G, Lärksäter M, Winblad B, Zetterberg H, Blennow K, Långström B, Nordberg A: Effect of phenserine treatment on brain functional activity and amyloid in Alzheimer's disease. Ann Neurol 2008, 63:621-631.

38. Maggini M, Vanacore N, Raschetti R: Cholinesterase inhibitors: drugs looking for a disease? PLoS Med 2006, 3:e140.

39. Connor B, Young D, Yan Q, Faull RL, Synek B, Dragunow M: Brain-derived neurotrophic factor is reduced in Alzheimer's disease. Brain Res Mol Brain Res 1997, 49:71-81.

40. Sugaya K, Kwak YD, Ohmitsu O, Marutle A, Greig NH, Choumrina E: Practical issues in stem cell therapy for Alzheimer's disease. Curr Alzheimer Res 2007, 4:370-377

41. Vrotsos EG, Sugaya K: MCP-1-induced migration of NT2 neuroprogenitor cells involving APP signaling. Cell Mol Neurobiol 2009, 29:373-381.

42. Marutle A, Ohmitsu M, Nilbratt M, Greig NH, Nordberg A, Sugaya K: Modulation of human neural stem cell differentiation in Alzheimer (APP23) transgenic mice by phenserine. Proc Natl Acad Sci U S A 2007, 104:12506-12511.

43. Kwak YD, Brannen CL, Qu T, Kim HM, Dong X, Soba P, Majumdar A, Kaplan A, Beyreuther K, Sugaya K: Amyloid precursor protein regulates differentiation of human neural stem cells. Stem Cells Dev 2006, 15:381-389.

44. Lu P, Jones LL, Snyder EY, Tuszynski MH: Neural stem cells constitutively secrete neurotrophic factors and promote extensive host axonal growth after spinal cord injury. Exp Neurol 2003, 181:115-129.

45. Zhao LR, Berra HH, Duan WM, Singhal S, Mehta J, Apkarian AV, Kessler JA: Beneficial effects of hematopoietic growth factor therapy in chronic ischemic stroke in rats. Stroke 2007, 38:2804-2811.

46. Zhao LR, Singhal S, Duan WM, Mehta J, Kessler JA: Brain repair by hematopoietic growth factors in a rat model of stroke. Stroke 2007, 38:2584-2591.

47. Zhu W, Mao Y, Zhao Y, Zhou LF, Wang Y, Zhu JH, Zhu Y, Yang GY: Transplantation of vascular endothelial growth factor-transfected neural stem cells into the rat brain provides neuroprotection after transient focal cerebral ischemia. Neurosurgery 2005, 57:325-333; discussion 325-333.

48. Bang OY, Lee JS, Lee PH, Lee G: Autologous mesenchymal stem cell transplantation in stroke patients. Ann Neurol 2005, 57:874-882.

49. Lee JS, Hong JM, Moon GJ, Lee PH, Ahn YH, Bang OY: A long-term follow-up study of intravenous autologous mesenchymal stem cell transplantation in patients with ischemic stroke. Stem Cells 2010, 28:1099-1106.

50. Glass CK, Saijo K, Winner B, Marchetto MC, Gage FH: Mechanisms underlying inflammation in neurodegeneration. Cell 2010, 140:918-934.

51. Feany MB, Bender WW: A Drosophila model of Parkinson's disease. Nature 2000, 404:394-398

52. Dawson TM, Dawson VL: Molecular pathways of neurodegeneration in Parkinson's disease. Science 2003, 302:819-822.

53. McKay R, Kittappa R: Will stem cell biology generate new therapies for Parkinson's disease? Neuron 2008, 58:659-661.

54. Park HJ, Lee PH, Bang OY, Lee G, Ahn YH: Mesenchymal stem cells therapy exerts neuroprotection in a progressive animal model of Parkinson's disease. J Neurochem 2008, 107:141-151.

55. Murrell W, Wetzig A, Donnellan M, Feron F, Burne T, Meedeniya A, Kesby J, Bianco J, Perry C, Silburn P, Mackay-Sim A: Olfactory mucosa is a potential source for autologous stem cell therapy for Parkinson's disease. Stem Cells 2008, 26:2183-2192.

56. Yasuhara T, Matsukawa N, Hara K, Yu G, Xu L, Maki M, Kim SU, Borlongan CV: 
Transplantation of human neural stem cells exerts neuroprotection in a rat model of Parkinson's disease. J Neurosci 2006, 26:12497-12511.

57. Kim JH, Auerbach JM, Rodriguez-Gomez JA, Velasco I, Gavin D, Lumelsky N, Lee SH, Nguyen J, Sanchez-Pernaute R, Bankiewicz K, McKay R: Dopamine neurons derived from embryonic stem cells function in an animal model of Parkinson's disease. Nature 2002, 418:50-56.

58. Wernig M, Zhao JP, Pruszak J, Hedlund E, Fu D, Soldner F, Broccoli V, Constantine-Paton M, Isacson O, Jaenisch R: Neurons derived from reprogrammed fibroblasts functionally integrate into the fetal brain and improve symptoms of rats with Parkinson's disease. Proc Natl Acad Sci U S A 2008, 105:5856-5861.

59. Cai J, Yang M, Poremsky E, Kidd S, Schneider JS, lacovitti L: Dopaminergic neurons derived from human induced pluripotent stem cells survive and integrate into 6-OHDA-lesioned rats. Stem Cells Dev 2010, 19:1017-1023.

60. Hideyama T, Yamashita T, Nishimoto Y, Suzuki T, Kwak S: Novel etiological and therapeutic strategies for neurodiseases: RNA editing enzyme abnormality in sporadic amyotrophic lateral sclerosis. J Pharmacol Sci 2010, 113:9-13.

61. Chi L, Ke Y, Luo C, Li B, Gozal D, Kalyanaraman B, Liu R: Motor neuron degeneration promotes neural progenitor cell proliferation, migration, and neurogenesis in the spinal cords of amyotrophic lateral sclerosis mice. Stem Cells 2006, 24:34-43.

62. Corti S, Locatelli F, Papadimitriou D, Del Bo R, Nizzardo M, Nardini M, Donadoni C, Salani S, Fortunato F, Strazzer S, Bresolin N, Comi GP: Neural stem cells LewisX+CXCR4+ modify disease progression in an amyotrophic lateral sclerosis model. Brain 2007, 130:1289-1305.

63. Magnus T, Carmen J, Deleon J, Xue H, Pardo AC, Lepore AC, Mattson MP, Rao MS, Maragakis NJ: Adult glial precursor proliferation in mutant SOD1G93A mice. Glia 2008, 56:200-208.

64. Lepore AC, Rauck B, Dejea C, Pardo AC, Rao MS, Rothstein JD, Maragakis NJ: Focal transplantation-based astrocyte replacement is neuroprotective in a model of motor neuron disease. Nat Neurosci 2008, 11:1294-1301.

65. Dimos JT, Rodolfa KT, Niakan KK, Weisenthal LM, Mitsumoto H, Chung W, Croft GF, Saphier G, Leibel R, Goland R, Wichterle H, Henderson CE, Eggan K: Induced pluripotent stem cells generated from patients with ALS can be differentiated into motor neurons. Science 2008, 321:1218-1221.

66. Mazzini L, Mareschi K, Ferrero I, Vassallo E, Oliveri G, Nasuelli N, Oggioni GD, Testa L, Fagioli F: Stem cell treatment in amyotrophic lateral sclerosis. J Neurol Sci 2008, 265:78-83.
67. Mazzini L, Ferrero I, Luparello V, Rustichelli D, Gunetti M, Mareschi K, Testa L, Stecco A, Tarletti R, Miglioretti M, Fava E, Nasuelli N, Cisari C, Massara M, Vercelli R, Oggioni GD, Carriero A, Cantello R, Monaco F, Fagioli F: Mesenchymal stem cell transplantation in amyotrophic lateral sclerosis: a phase I clinical trial. Exp Neurol 2010, 223:229-237.

68. Weiner $\mathrm{HL}$ : The challenge of multiple sclerosis: how do we cure a chronic heterogeneous disease? Ann Neurol 2009, 65:239-248.

69. Harrison DM, Calabresi PA: Promising treatments of tomorrow for multiple sclerosis. Ann Indian Acad Neurol 2009, 12:283-290.

70. Aharonowiz M, Einstein O, Fainstein N, Lassmann H, Reubinoff B, Ben-Hur T: Neuroprotective effect of transplanted human embryonic stem cellderived neural precursors in an animal model of multiple sclerosis. PLoS One 2008, 3:e3145.

71. Pluchino S, Zanotti L, Brini E, Ferrari S, Martino G: Regeneration and repair in multiple sclerosis: the role of cell transplantation. Neurosci Lett 2009, 456:101-106.

72. Burt RK, Loh Y, Cohen B, Stefoski D, Balabanov R, Katsamakis G, Oyama Y, Russell EJ, Stern J, Muraro P, Rose J, Testori A, Bucha J, Jovanovic B, Milanetti F, Storek J, Voltarelli JC, Burns WH: Autologous non-myeloablative haemopoietic stem cell transplantation in relapsing-remitting multiple sclerosis: a phase I/II study. Lancet Neurol 2009, 8:244-253.

73. Sugarman J: Human stem cell ethics: beyond the embryo. Cell Stem Cell 2008, 2:529-533.

74. Hyun I, Lindvall O, Ahrlund-Richter L, Cattaneo E, Cavazzana-Calvo M, Cossu G, De Luca M, Fox IJ, Gerstle C, Goldstein RA, Hermerén G, High KA, Kim HO, Lee HP, Levy-Lahad E, Li L, Lo B, Marshak DR, McNab A, Munsie M, Nakauchi H, Rao M, Rooke HM, Valles CS, Srivastava A, Sugarman J, Taylor PL, Veiga A, Wong AL, Zoloth L, Daley GQ: New ISSCR guidelines underscore major principles for responsible translational stem cell research. Cell Stem Cell 2008, 3:607-609.

doi:10.1186/scrt37

Cite this article as: Dantuma E, et al:. Stem cells for the treatment of neurodegenerative diseases. Stem Cell Research \& Therapy 2010, 1:37. 